\title{
Design of hydraulic recuperation unit
}

\author{
Pavel Jandourek ${ }^{1, a}$, Vladimír Habán ${ }^{1}$, Martin Hudec ${ }^{1}$, Lenka Dobšáková ${ }^{1}$ and David Štefan ${ }^{1}$ \\ ${ }^{1}$ Brno University of Technology, Faculty of Mechanical Engineering, Energy Institute, Victor Kaplan Department of Fluid Engineering, \\ Technicka 2896/2, 61669 Brno, Czech Republic
}

\begin{abstract}
This article deals with design and measurement of hydraulic recuperation unit. Recuperation unit consist of radial turbine and axial pump, which are coupled on the same shaft. Speed of shaft with impellers are 6000 1/min. For economic reasons, is design of recuperation unit performed using commercially manufactured propellers.
\end{abstract}

\section{Introduction}

This article deals with the study of recuperation unit, which would use excess pressure energy to propel the liquid. Recuperation device consists of a radial turbine and an axial pump, whose normal wheels rotates at the same speed and can be on a common shaft or separated by a magnetic coupling. Construction must be secured tightness of the turbine and pump circuit.

\section{The suggestion of solution}

According to set parameters are determined the dimensions of the hydraulic machines.

Table 1. Design parameters.

\begin{tabular}{|c|c|}
\hline \multicolumn{2}{|c|}{ Design parameters of turbine } \\
\hline Head $\mathrm{H}_{\mathrm{T}}$ & $10 \mathrm{~m}$ \\
\hline Turbine flow $\mathrm{Q}_{\mathrm{T}}$ & $0.5 \mathrm{l} / \mathrm{s}$ \\
\hline Design parameters of pump \\
\hline Specific energy $\mathrm{Y}$ & $13.5 \mathrm{~J} / \mathrm{kg}$ \\
\hline Pump flow $\mathrm{Q}_{\mathrm{P}}$ & $1 \mathrm{l} / \mathrm{s}$ \\
\hline
\end{tabular}

Turbine Pump

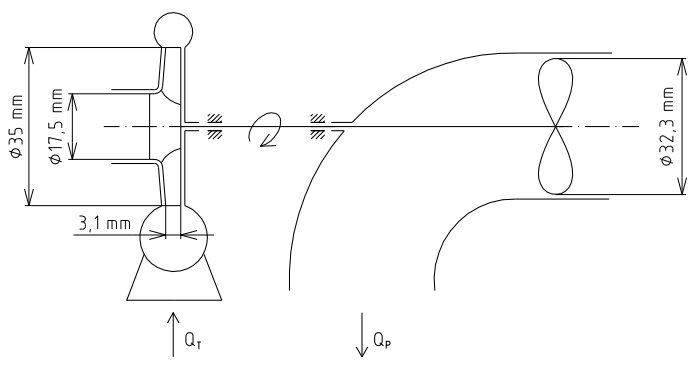

Figure 1. Diagram of recuperation unit.

\footnotetext{
a Corresponding author: y101051@stud.fme.vutbr.cz
}

\subsection{Model of radial turbine}

The turbine is designed to specified parameters. To better guide the water to the runner is used diffuser. The shaft is mounted in plain bearings, that are lubricated with water. Spiral case and runner are made using 3D printing. Spiral surface is painted, in order to avoid water seepage through the surfaces of turbine.

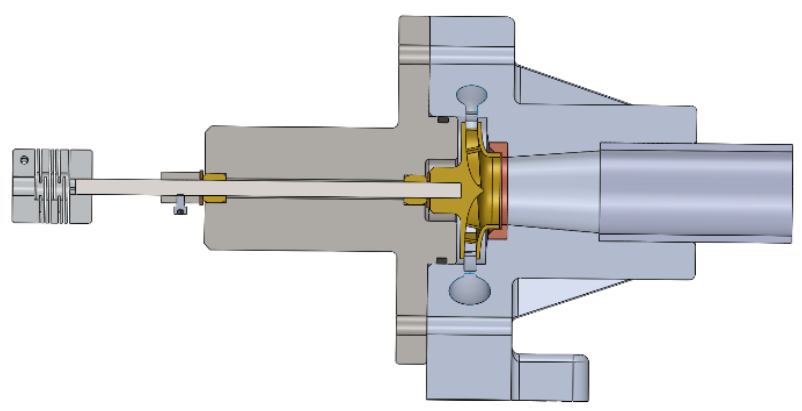

Figure 2. Cut of radial turbine.

\subsection{Model of axial pump}

The impeller is pressed onto the overhung shaft, which is led out of the elbow. They are used in plain bearings lubricated with water. Axial force on the impeller is captured by axial plain bearings below impeller and before the sleeve. Between a straight piece of pipe and elbow could be bet the diffuser, which directing swirling fluid behind the impeller.

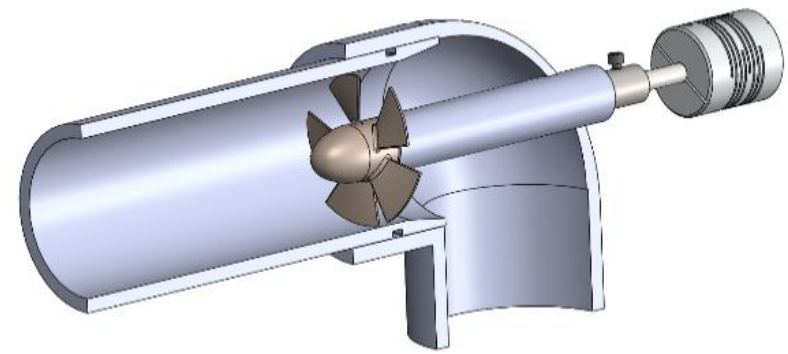

Figure 3. Cut of axial pump. 


\subsection{Recuperation unit}

Recuperation unit is formed by the merger turbine and pump.

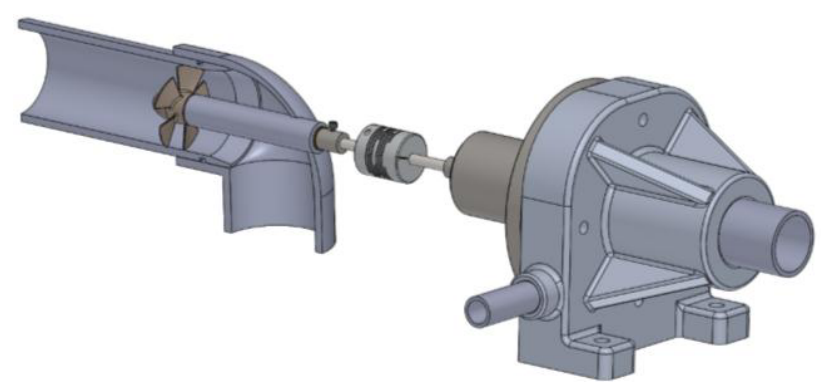

Figure 4. Cut of recuperation unit.

\section{Development and measurement}

\subsection{Measurement of turbine}

Measuring rig for turbine is composed of a suction tank, which serves as a liquid reservoir, the suction and discharge pipes and the feeding pump with variable speed drive. For feed pump is included a flowmeter and the measured turbine. On the discharge line is positioned throttle valve. Torquemeter for measuring output, torque and speed is attached bellows couplings between the pump and motor. The electric motor has a speed drive. There are two pressure sensors on the measurement rig. One is in suction pipe and second is in discharge piping. For donations of pressure and flow are observed length to calm the roiling of flowing liquid. Pressure sensors are powered by a stabilized source.

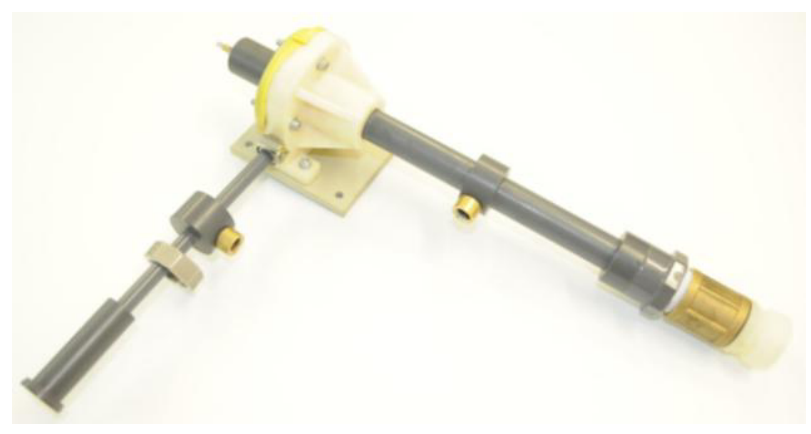

Figure 5. Turbine with stilling sections.

Table 2. Measured quantities at the turbine.

\begin{tabular}{|c|c|c|}
\hline $\mathrm{p}_{1}$ & pressure in discharge tube & $\mathrm{Pa}$ \\
\hline $\mathrm{p}_{2}$ & pressure in suction tube & $\mathrm{Pa}$ \\
\hline $\mathrm{Q}$ & flow & $\mathrm{m}^{3} / \mathrm{s}$ \\
\hline $\mathrm{M}_{\mathrm{k}}$ & torque & $\mathrm{Nm}$ \\
\hline $\mathrm{P}_{\text {out }}$ & output & $\mathrm{W}$ \\
\hline $\mathrm{n}$ & speed & $1 / \mathrm{s}$ \\
\hline
\end{tabular}

Measurement procedure - after flooding rig and subsequent venting set the turbine speed. Feed pump settles to the required pressure drop. Let it steady and save the measured values. We continue adjusting other operating points with different speeds until to measure whole characteristic of the turbine. Shutting turbines perform gradually decreasing head and speed of the turbine. To determine the difference of values in sensors measure the pressure difference in the measurement rig in calm state and then drain the water from it. Saved mean values will be used to determine the functional dependence $\mathrm{Q} 11=\mathrm{f}(\mathrm{n} 11), \eta=\mathrm{f}(\mathrm{n} 11)$. The resulting characteristics create polynomial fitting the computed points.

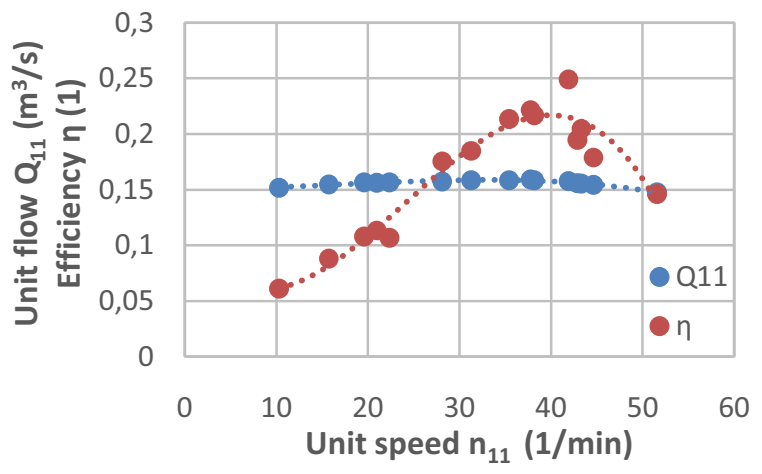

Figure 6. Dependence of unit flow and efficiency on unit speed.

Dependence of torque $\mathrm{M}_{\mathrm{k}}$ on turbine flow is recalculated for different values speed of runner.

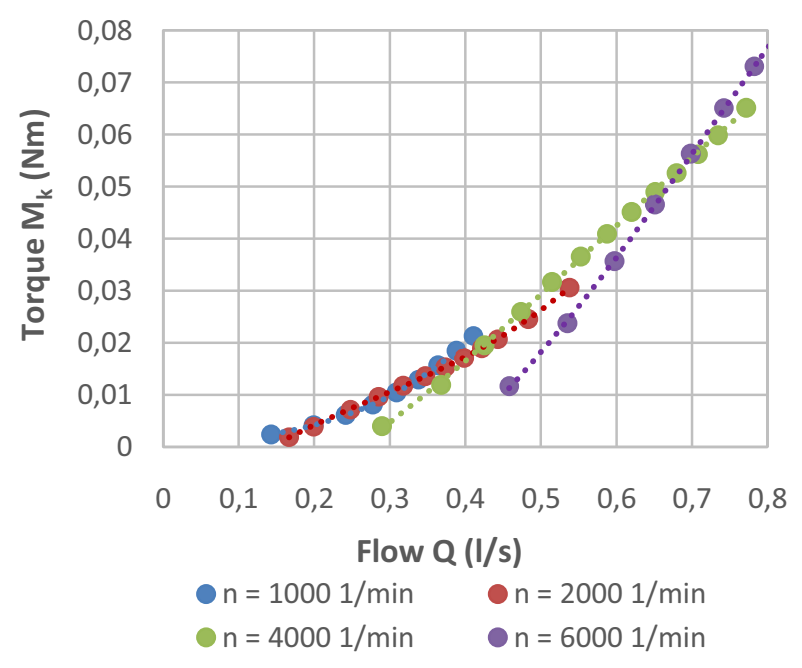

Figure 7. Torque of turbine in dependence on flow for values of speed between 1000 until 6000 1/rpm.

\subsection{Measurement of pump}

Measuring rig for pump is composed of a suction tank, which serves as a liquid reservoir, the suction and discharge pipes and the feeding pump with variable speed drive. For feed pump is included a flow meter and the measured axial pump. On the discharge line is positioned throttle valve. Torque meter for measuring output, torque and speed is attached bellows couplings between the pump and motor. The electric motor has a speed drive. 
There are two pressure sensors on the measurement rig. One is in suction pipe and second is on discharge piping.

Impellers proposal was made by its own program operating on the principle of differential geometry. Due to the extremely poor quality of surface axial impellers made by using 3D printing, have been purchased for the development of pumps 3 propellers, designed for marine modellers.
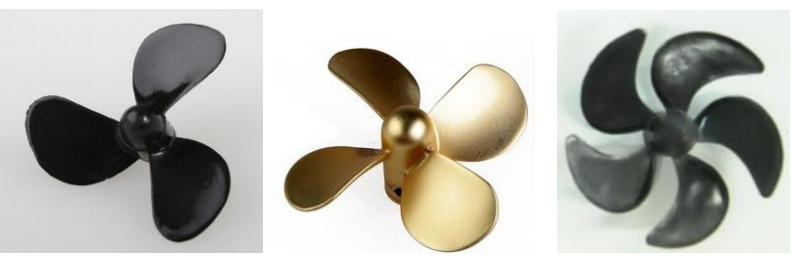

Figure 8. 3,4 a 5 bladed ship impellers with diameter $40 \mathrm{~mm}$.

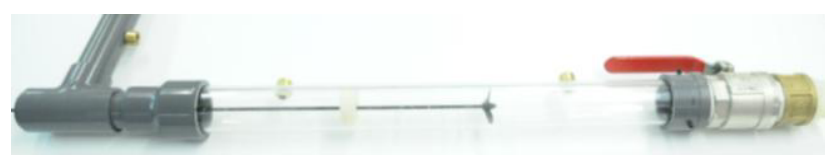

Figure 9. A device for measurement of the ship propellers with a diameter $40 \mathrm{~mm}$.

Table 3. Measured quantities at the pump.

\begin{tabular}{|c|c|c|}
\hline $\mathrm{p}_{1}$ & pressure in suction tube & $\mathrm{Pa}$ \\
\hline $\mathrm{p}_{2}$ & pressure in discharge tube & $\mathrm{Pa}$ \\
\hline $\mathrm{Q}$ & flow & $\mathrm{m}^{3} / \mathrm{s}$ \\
\hline $\mathrm{M}_{\mathrm{k}}$ & torque & $\mathrm{Nm}$ \\
\hline $\mathrm{P}_{\mathrm{in}}$ & power & $\mathrm{W}$ \\
\hline $\mathrm{n}$ & speed & $1 / \mathrm{s}$ \\
\hline
\end{tabular}

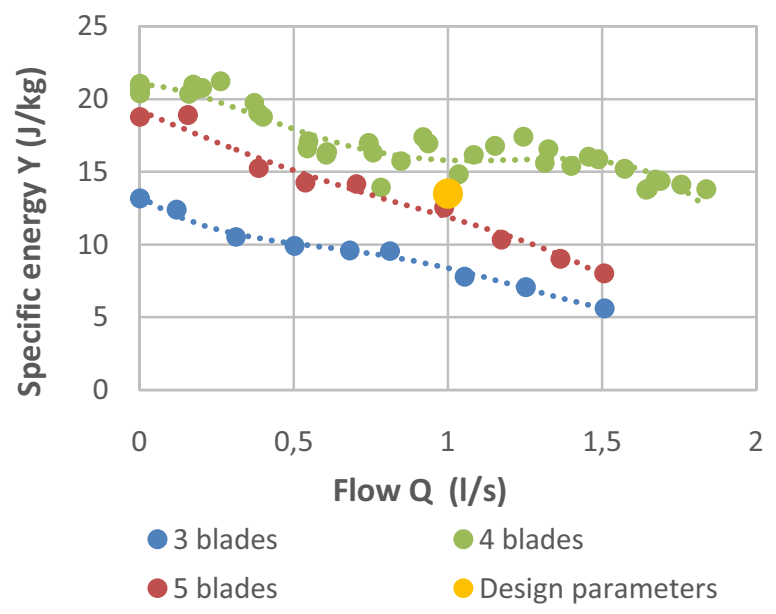

Figure 10. Dependence of specific energy on flow.

Best values while meeting the parameters of the design point reached propeller of diameter $40 \mathrm{~mm}$ with 4 blades.

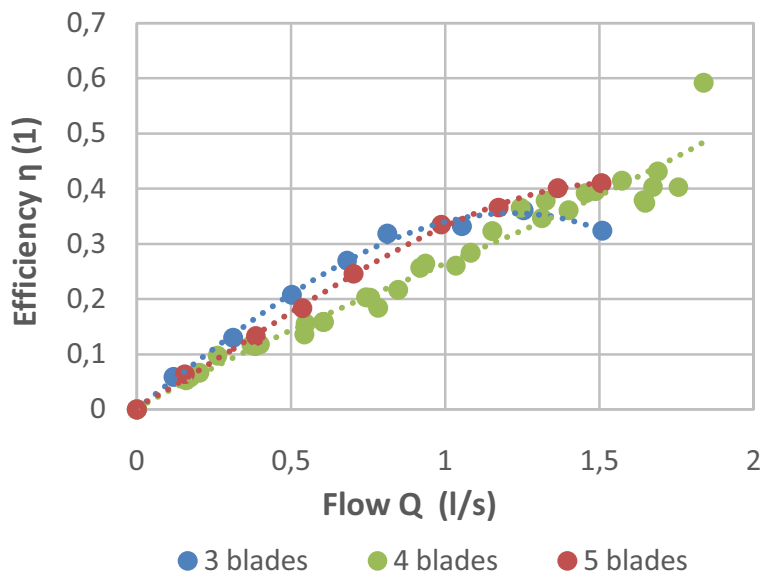

Figure 11. Dependence of efficiency on flow.

Propeller was machined from 40 to $33 \mathrm{~mm}$, and was made a new hub. To be used propeller as a impeller of the axial pump, propeller must be additionally rotated. This will maintain the correct direction of flow through the pump.
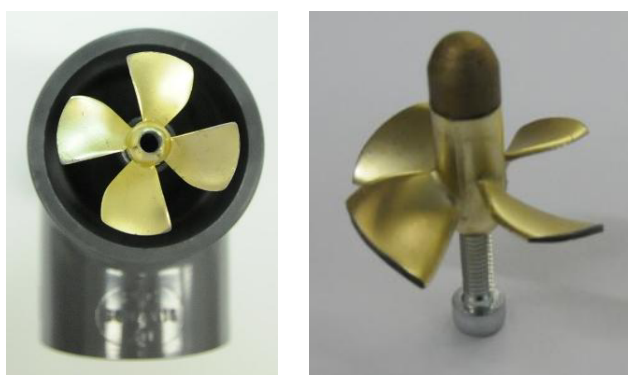

Figure 12. Rotated ship propeller with drilled hub and machined on diameter $33 \mathrm{~mm}$.

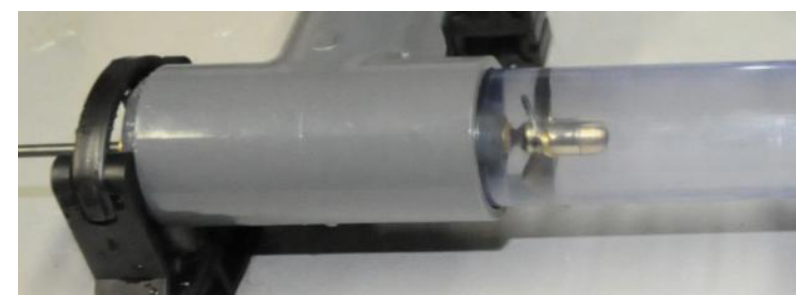

Figure 13. Adjusted propeller in the measuring circuit.

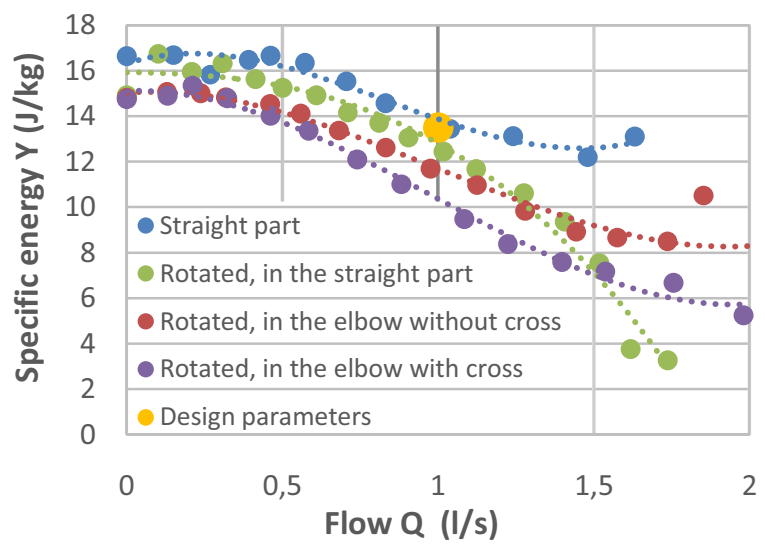

Figure 14. Dependence of specific energy on flow. 


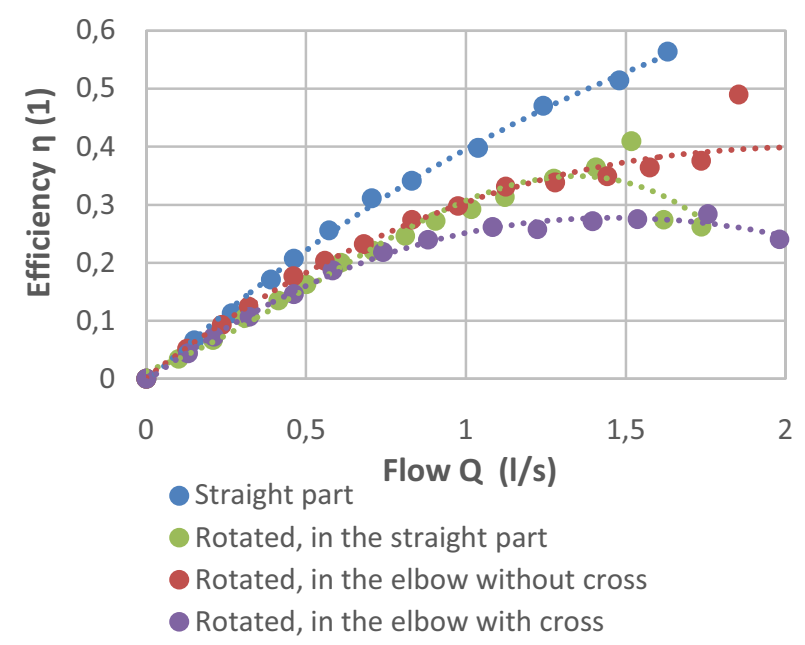

Figure 15. Dependence of efficiency on flow.

The best hydraulic profile of impeller for axial pump was created using the propeller machined from 40 to $33 \mathrm{~mm}$. The specific energy characteristic is slightly smaller than the design point. This is caused by hydraulic losses in the piping system.

\section{Recuperation unit}

On the left side is circuit of turbine. The turbine is driven by the feeding pump. On the right side is the pump circuit, which is to pump water through the spillway. The turbine and the pump is fixed.

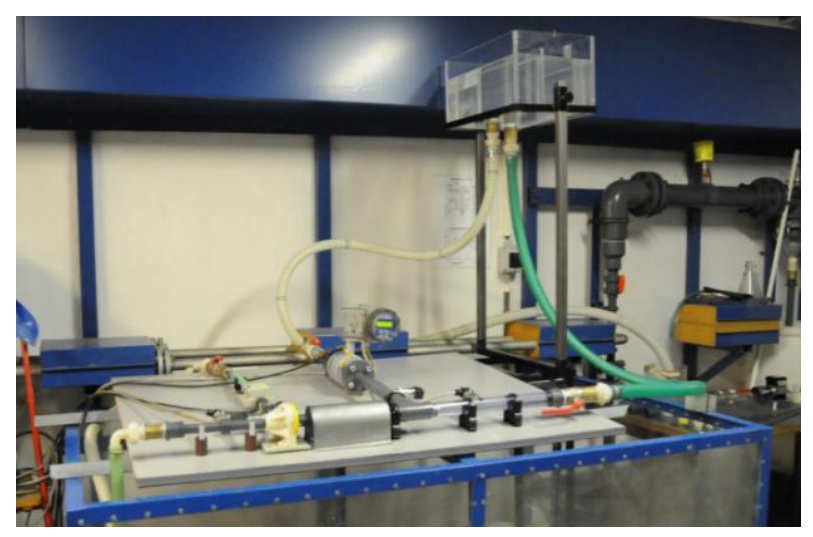

Figure 16. Test rig of recuperation unit.

The following graph shows the dependence of the flow on the pump flow turbine.

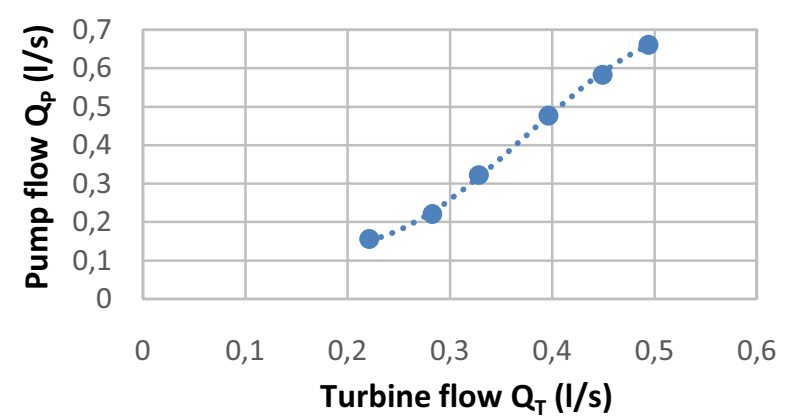

Figure 17. Dependence of pump flow on turbine flow.
Dependence of pressure losses on the turbine on the turbine flow shows resistive characteristics.

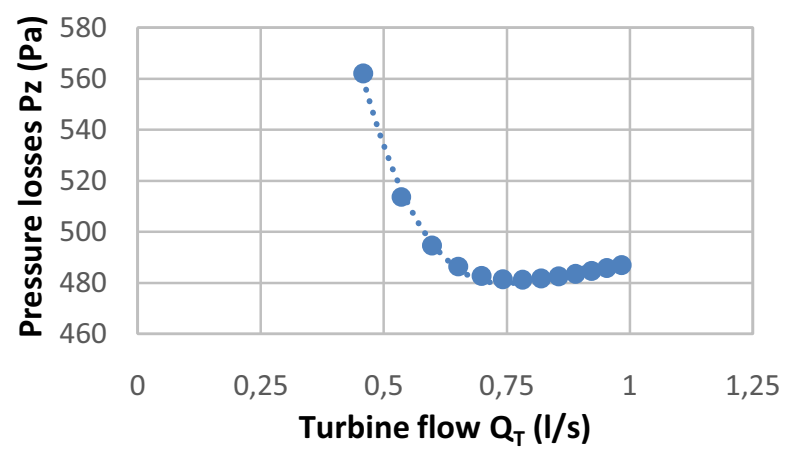

Figure 18. Resistive characteristics.

\section{Conclusion}

Hydraulic design of a turbine and a pump for the specified parameters recuperation unit was executed. These are the radial and axial turbine pump. These two machines work at the same speed. The turbine drives an axial pump and the pump pumps liquid.

According to the design has been using the method of $3 \mathrm{D}$ printing made turbine with these hydraulic parameters (Fig. 6. and 7.).

Axial pump was also made using 3D printing technology, but the results of multiple variants were not satisfactory. Especially the influence of roughness printed 3D models and the effect of the gap between the blades and stator, led to very low efficiency and failure to comply with the required hydraulic parameters. The final design consisted in the use of commercial hydraulic of the modelling propeller, which after tests achieved the required flow rate and efficiency

Fig. 7. shows the flow of water from the storage tank, depending on the water flow turbine calculated according to specified parameters. By entering the flow of the water pump $1.034 \mathrm{l} / \mathrm{s}$. Hydraulics achieve with current flow $0.66 \mathrm{l} / \mathrm{s}$. It could be assumed, that the efficiency (output) turbine produced by a other method than $3 \mathrm{D}$ printing, will be significantly higher and the pump will reach a higher flow rate. The models produced by $3 \mathrm{D}$ printing have high roughness value that the flow is causing high losses. Measured the efficiency of the turbine was up $24 \%$. By reducing the roughness of the hydraulic space can be expected to increase the efficiency to $35-45 \%$. Using hydraulics, i.e. hydraulic of pump and turbine can be designed a functional sample of recuperation unit. It can assume, that the parameters will be better than the corresponding Fig. 7., particularly with regard to the lower surface and smaller mechanical losses of prototype. In future prototype of recuperation unit would be appropriate to measure hydraulically again.

\section{Acknowledgement}

Presented research was supported by center of competence of Technology Agency of The Czech Republic TE02000232 "Rotary machines". 